\title{
Usefulness of Transnasal Argon Plasma Coagulation for Esophageal Varices Compared with the Peroral Method: A Randomized and Prospective Clinical Study
}

\author{
Yoshihiro Furuichi $^{\mathrm{a}}$ Takashi Kawai $^{\mathrm{b}}$ Shigeki Ichimurac ${ }^{\mathrm{C}}$ Yuki Miyata $^{\mathrm{a}}$ \\ Takatomo Sano $^{a}$ Eigaku Murashima ${ }^{a}$ Junichi Taira ${ }^{a}$ Katsutoshi Sugimoto ${ }^{a}$ \\ Yasuharu Imai $^{a}$ Ikuo Nakamura ${ }^{a}$ Fuminori Moriyasu ${ }^{a}$ \\ a Department of Gastroenterology and Hepatology and ${ }^{\mathrm{b}}$ Endoscopy Center, Tokyo Medical University, Tokyo, and \\ 'Department of Gastroenterology, Toda Chuo General Hospital, Saitama, Japan
}

\section{Key Words}

Argon plasma coagulation $\cdot$ Varices $\cdot$ Sedation $\cdot$ Transnasal endoscope $\cdot$ Liver cirrhosis

\begin{abstract}
Background: Argon plasma coagulation (APC) is very useful as a consolidation treatment for reducing the recurrence of esophageal varices (EVs). However, repeated sedation in endoscopic treatment has the risk of prolonging hepatic encephalopathy and affects the respiratory state of liver cirrhosis (LC) patients, in whom pulmonary arteriovenous shunts are observed. We evaluated prospectively whether transnasal endoscopic APC without sedation is more effective than peroral endoscopic APC with sedation. Patients and Methods: LC patients $(n=101)$, treated by endoscopic injection sclerotherapy to eradicate EVs, were randomly divided into a transnasal APC group $(n=50)$ and a peroral APC group $(n=51)$. The primary efficacy endpoint was the cumulative recurrence rate of EVs. The secondary endpoints were blood pressure (BP), heart rate, oxygen saturation during APC and complications. Results: There was no significant difference in the cumulative recurrence rate of EVs at 36 months between the transnasal APC and peroral APC groups (35.0 vs.
\end{abstract}

$40.8 \%, p=0.39$, log-rank test), indicating that transnasal APC is not inferior to peroral APC. The transnasal APC group showed more stable intraoperative BP and oxygen saturation values, and a lower incidence of epigastralgia (56.0 vs. $74.5 \%, p=0.04)$. Conclusion: The efficacy of reducing the recurrence of EVs in the transnasal APC group was not significantly different from that in the peroral APC group. Transnasal APC caused less distress and required no sedation. Therefore, this method was more advantageous for LC patients at risk of suffering from prolongation of hepatic encephalopathy.

Copyright $\odot 2013$ S. Karger AG, Basel

\section{Introduction}

Argon plasma coagulation (APC) is effective for reducing recurrence after eradication of esophageal varices (EVs) by endoscopic injection sclerotherapy (EIS) or endoscopic variceal ligation (EVL), since inducing fibrosis on the esophageal mucosa is essential to prevent this recurrence $[1,2]$. APC is a non-contact thermal coagulation method in which high-frequency electric current is sent to the target tissue through an argon plasma jet. A

\section{KARGER}

Fax +41613061234

E-Mail karger@karger.ch

www.karger.com
(C) 2013 S. Karger AG, Basel

0012-2823/13/0871-0017\$38.00/0

Accessible online at:

www.karger.com/dig
Yoshihiro Furuichi, MD, PhD

Fourth Department of Internal Medicine

Tokyo Medical University

6-7-1 Nishishinjuku, Shinjuku-ku, Tokyo 160-0023 (Japan)

E-Mail furuichi@tokyo-med.ac.jp 
distinctive characteristic of APC is the safe and effective shallow coagulation over extensive areas [3]. However, since it is performed with an endoscope, conventional APC requires sedation to reduce patient discomfort. Liver patients are at potentially greater risk of complications, including cardiopulmonary compromise, and possible precipitation or exacerbation of encephalopathy, including sub-clinical encephalopathy $[4,5]$. Recently, the negative effects of using midazolam sedation during peroral endoscopic examination, such as prolonging hepatic encephalopathy in liver cirrhosis (LC) patients, have been reported $[4,6,7]$. Moreover, there were some reports that the risk of hypoxemia, bradycardia and hypotension increased during moderate sedation $[8,9]$. Since pulmonary arteriovenous shunts are often accompanied by LC as cardiopulmonary compromise [10], the risk of hypoxemia is higher than that in a healthy population [11].Therefore, if a new endoscopic APC method, causing less discomfort without using sedation, were developed, it would provide a significant improvement for LC patients.

Transnasal endoscopy has attracted much interest because it causes little distress to patients and the examination can be performed without using sedation $[10,12]$. In this study, we used a transnasal endoscope without sedation and performed APC to induce fibrosis of the esophageal mucosa after eradication of the EVs using EIS. The aim of this randomized study was to assess prospectively the efficacy of transnasal APC, compared with peroral APC, for the prevention of recurrence of EVs.

\section{Patients and Methods}

\section{Patients and Procedures}

A total of 101 LC patients with high-risk EVs, which were subsequently eradicated by EIS at our hospital, were enrolled in this study. This phase II study was conducted prospectively, with 50 patients being randomly assigned to receive transnasal APC without sedation and 51 patients assigned to receive peroral APC with sedation. After obtaining approval from the Ethics Committee of our institution, patients from whom written informed consent had been obtained were enrolled as subjects. Emergency cases, patients receiving anticoagulants, or patients with advanced cardiopulmonary disease, nasal obstruction or thrombocytopenia (platelet count $<2.0 \times 10^{4} / \mu \mathrm{l}$ ), were excluded. This study protocol conformed to the principles of the 1975 Helsinki Declaration. Randomization was performed using a computer-generated random number technique. The 2 groups were comparable for all background variables, including age, classification of EVs and the Child-Pugh score (table 1). APC therapy was initiated within 14 days of variceal eradication. Eradication was defined as the complete disappearance of varices, and variceal recurrence was de-
Table 1. Baseline characteristics of the patients according to study group

\begin{tabular}{|c|c|c|c|}
\hline Characteristics & $\begin{array}{l}\text { Transnasal } \\
\text { APC } \\
(n=50)\end{array}$ & $\begin{array}{l}\text { Peroral } \\
\text { APC } \\
(n=51)\end{array}$ & $\begin{array}{l}\mathrm{p} \\
\text { value }\end{array}$ \\
\hline Age, years & $64.7 \pm 11.1$ & $64.5 \pm 12.1$ & 0.55 \\
\hline Male/female & $37 / 13$ & $36 / 15$ & $0.70^{\dagger}$ \\
\hline Etiology of LC & & & $0.23^{\dagger}$ \\
\hline Viral hepatitis & 22 & 32 & \\
\hline Non-B non-C hepatitis & 6 & 4 & \\
\hline Alcoholic hepatitis & 15 & 13 & \\
\hline IPH, PBC, AIH & 6 & 2 & \\
\hline Follow-up period, months & $20.5 \pm 15.6$ & $19.0 \pm 14.3$ & 0.61 \\
\hline \multicolumn{4}{|l|}{ Variceal classification type } \\
\hline$(\mathrm{F} 1 / \mathrm{F} 2 / \mathrm{F} 3)$ & $16 / 20 / 14$ & $17 / 21 / 13$ & $0.96^{\dagger}$ \\
\hline Child-Pugh score & $6.1 \pm 1.1$ & $6.1 \pm 1.0$ & 0.90 \\
\hline Sessions of EIS & $2.6 \pm 1.3$ & $2.8 \pm 1.1$ & 0.50 \\
\hline \multicolumn{4}{|l|}{ Blood test results } \\
\hline PT-INR, s & $1.1 \pm 0.1$ & $1.1 \pm 0.1$ & 0.80 \\
\hline Platelets, $\times 10^{4} / \mu \mathrm{l}$ & $9.1 \pm 5.0$ & $8.4 \pm 5.4$ & 0.48 \\
\hline AST, IU/1 & $41.1 \pm 16.2$ & $47.1 \pm 27.3$ & 0.18 \\
\hline ALT, IU/l & $27.2 \pm 16.2$ & $31.2 \pm 18.6$ & 0.23 \\
\hline Total bilirubin, mg/dl & $1.2 \pm 0.5$ & $1.2 \pm 0.7$ & 0.50 \\
\hline Albumin, g/dl & $3.4 \pm 0.5$ & $3.3 \pm 0.5$ & 0.50 \\
\hline Cholinesterase, IU/1 & $168.8 \pm 65.1$ & $151.5 \pm 74.3$ & 0.22 \\
\hline Ammonia, $\mu \mathrm{g} / \mathrm{dl}$ & $73.4 \pm 30.9$ & $81.7 \pm 42.1$ & 0.28 \\
\hline
\end{tabular}

Data are expressed as mean $\pm \mathrm{SD}$. The Student t test was used for the comparison of values. ${ }^{\dagger}$ Differences for each characteristic were tested with the $\chi^{2}$ test. A p value of less than 0.05 was considered to indicate a statistically significant difference. IPH = Idiopathic portal hypertension; PBC = primary biliary cirrhosis; $\mathrm{AIH}=$ autoimmune hepatitis; PT-INR = prothrombin time international normalized ratio; AST $=$ aspartate aminotransferase; ALT $=$ alanine aminotransferase.

fined as the development of varices of classification type F1 or greater, occurrence of the red color sign or recurrent variceal bleeding. A single operator performed all APC treatments. APC was performed in just 1 session as the mucosa-fibrosing therapy in each case. After EVs had been treated by EIS and APC, patients underwent endoscopy every 4 months until the end of the followup period (from August 2007 to February 2012).

\section{APC Equipment, Settings and Usage Based on Basic}

Experiment

The endoscopes used were the Fujinon EG-530N2 or NW (Fujinon Corp., Saitama, Japan) transnasal endoscope, and the EG590WR or WR2 (Fujinon Corp.) peroral endoscope. Both endoscopic tips were coated with insulating material and were suited for APC. APC was performed with a high-frequency generator (APC300, ICC200; ERBE Elektromedizin GmbH, Tübingen, Germany), a flexible $1.5-\mathrm{mm}$-diameter axial probe for the transnasal endoscope and a 2.2-mm-diameter axial probe for the peroral en- 

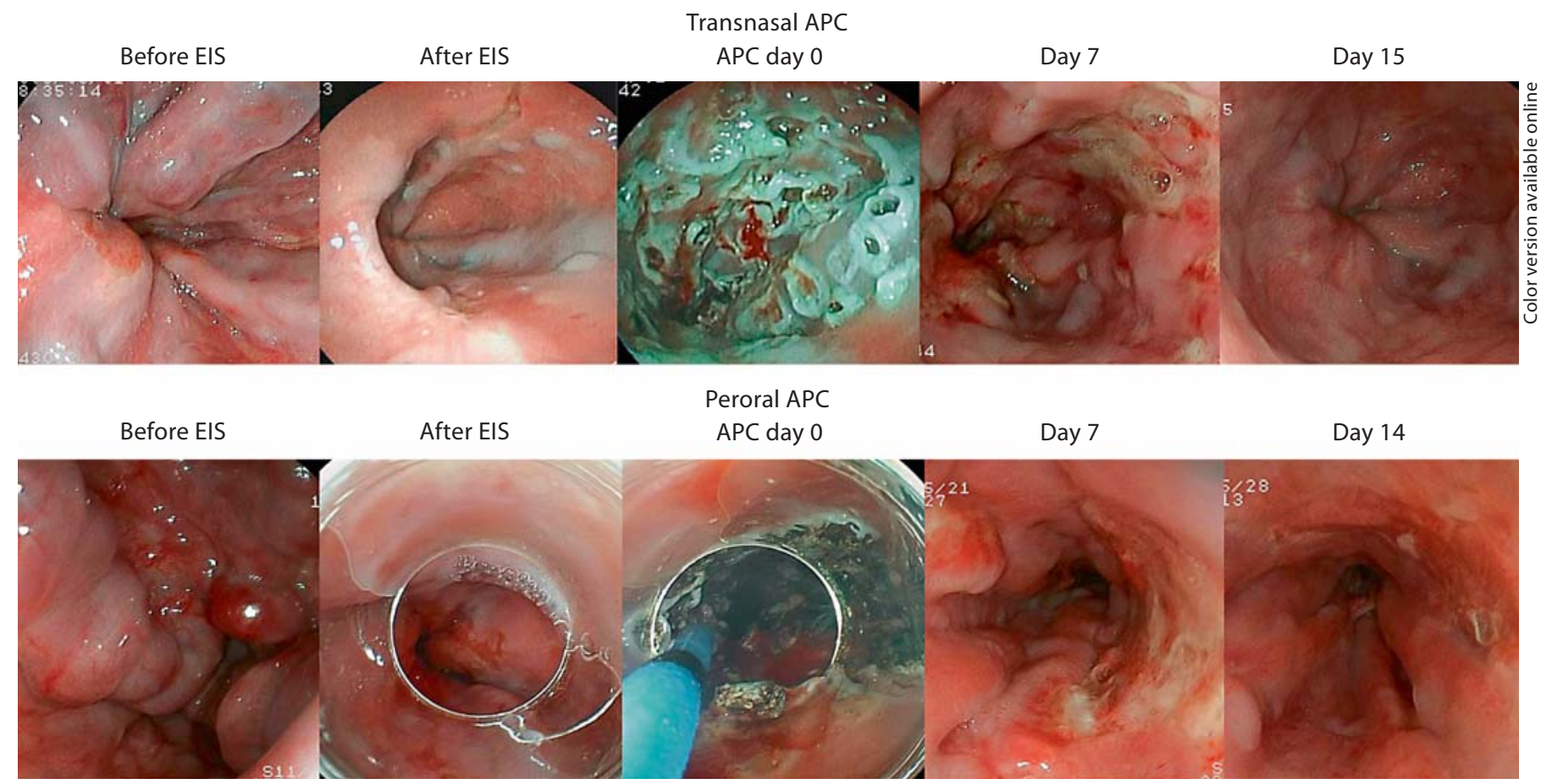

Fig. 1. Endoscopic findings after APC in both cases. Shallow ulceration of the coagulated surface with an adherent fibrin coagulum was noted in all patients 7 days after each APC treatment. There was no significant difference for the healing period of treatment ulcers in both groups.

doscope. As described in previous reports [1, 2, 13-15], peroral APC was set with an argon gas flow rate of 1.8 liters $/ \mathrm{min}$ and an arc output of $60 \mathrm{~W}$. In contrast, the maximum power of the 1.5-mm-diameter axial probe for transnasal APC had the following limitations: a flow rate of 0.5 liters $/ \mathrm{min}$ and an arc output of $40 \mathrm{~W}$.

Because of the above-mentioned limitations, a preliminary animal experiment was conducted in 5 esophagus areas using 3 ex vivo porcine models to compare cauterizing capabilities. APC pulse duration times were set at 1, 3, 5, 7 and $10 \mathrm{~s}$ and the cauterizing capabilities were estimated using both probes. When cauterization was applied for 3 or $5 \mathrm{~s}$, the resulting effects of transnasal and peroral APC probes on the mucosa were comparable. Evaluated with a scoring system - (1) epithelium, (2) lamina propria, (3) muscularis mucosa, (4) upper submucosa, (5) lower submucosa, and (6) muscularis propria - the median values of tissue defects for 3 (or 5) s of cauterization with transnasal probe and peroral probe were $2.0(2.0)$ points and $2.0(3.0)$ points $[\mathrm{p}=0.42$ (0.067), Mann-Whitney U test], and those of tissue degeneration were $3.0(3.0)$ points and $3.0(3.0)$ points $(\mathrm{p}=0.18)$. However, there were significant differences for tissue effect of cauterization time of 1,7 and $10 \mathrm{~s}$. When endoscopic APC experiments with both probes were performed on whole esophagus of 2 ex vivo porcine models under the setting of a pulse duration time of $3 \mathrm{~s}$, the depth of tissue defects on 43 sites cauterized by transnasal APC and those on 40 sites by peroral APC were comparable $(\mathrm{p}=0.071)$. Therefore, all APC treatments were performed, with the setting of a pulse duration time of $3 \mathrm{~s}$, on the entire circumference of the distal esophagus from the esophagogastric junction to about $5 \mathrm{~cm}$ towards the proximal segment.

\section{Efficacy Assessment and Statistical Analysis}

The primary efficacy endpoint of this study was the cumulative recurrence rate of EVs. The secondary endpoints were intraoperative blood pressure (BP), heart rate, oxygen saturation $\left(\mathrm{SpO}_{2}\right)$, operating time and complications.

Intention-to-treat analysis was performed using SPSS 16.0 J software (SPSS Inc., Chicago, Ill., USA). Values were presented as means \pm standard deviation (SD). As all clinical data had a normal distribution, the Student $t$ test was used for the comparison of values between the 2 groups. The $\chi^{2}$ test was used for the comparison of gender, and the Fisher exact test for the incidence of complications. The cumulative recurrence rate curves were determined by the Kaplan-Meier method and were analyzed by the log-rank test. A p value of less than 0.05 was considered to indicate a statistically significant difference.

Required sample size was determined as follows. A power calculation was performed assuming a probability of variceal recurrence of about $50 \%$ at 24 months $[15,16]$. It was previously demonstrated that peroral APC achieved a 55\% reduction in the recurrence rate of EVs (from 50 to 22.5\%) compared with the non-APC-treated group [1]. Assuming an $\alpha$-error of 0.05 , a power of 0.80 and a $10 \%$ loss to follow-up observation, the required sample size was found to be 96 patients. 
Table 2. Operation-related data and complications according to study group

\begin{tabular}{lclc}
\hline & $\begin{array}{l}\text { Transnasal } \\
\text { APC } \\
(\mathrm{n}=50)\end{array}$ & $\begin{array}{l}\text { Peroral } \\
\text { APC } \\
(\mathrm{n}=51)\end{array}$ & $\begin{array}{l}\mathrm{p} \\
\text { value }\end{array}$ \\
& $8: 13$ & $7: 32$ & 0.22 \\
\hline Treatment time, min:s & $0.7 \pm 0.4$ & $2.1 \pm 0.9$ & $<0.0001$ \\
Argon gas flow volume, liters & $80.1 \pm 31.3$ & $81.9 \pm 23.5$ & 0.79 \\
APC shot times & $28(56.0)$ & $38(74.5)$ & 0.04 \\
Complications & $15(30.0)$ & $28(54.9)$ & 0.01 \\
$\quad$ Epigastralgia & $9(18.0)$ & $12(23.5)$ & 0.33 \\
Hypertension & $9(18.0)$ & $11(21.6)$ & 0.42 \\
Hypoxemia & $2(4.0)$ & $1(2.0)$ & 0.49 \\
Tachycardia & $1(2.0)$ & $3(5.9)$ & 0.32 \\
Postoperative bleeding & $1(2.0)$ & $0(0.0)$ & 0.50 \\
Stricture & & & \\
Epistaxis & & &
\end{tabular}

Data are expressed as mean $\pm \mathrm{SD}$ and values in parentheses are percentages. The Student $t$ test was used for the comparison of values of operation-related data. The Fisher exact test was used for the comparison of incidence of complications. A p value of less than 0.05 was considered to indicate a statistically significant difference.

\section{Results}

The number of EIS sessions required for achieving eradication before APC was $2.6 \pm 1.3$ for the transnasal APC group and $2.8 \pm 1.1$ for the peroral APC group ( $\mathrm{p}=0.5$, Fisher's exact test). The mean follow-up period was $20.5 \pm 15.6$ and $19.0 \pm 14.3$ months. The shot times of APC coagulation were $80.1 \pm 31.3$ and $81.9 \pm 23.5$ $(\mathrm{p}=0.78)$. The treatment time was slightly longer in the transnasal APC group, but there was no significant difference ( 8 min $13 \mathrm{~s}$ vs. $7 \mathrm{~min} 32 \mathrm{~s}, \mathrm{p}=0.22$ ). The transnasal APC group exhibited a significantly smaller total amount of argon gas flow ( $0.7 \pm 0.4$ vs. $2.1 \pm 0.9$ liters, $\mathrm{p}<0.0001$; table 2). Shallow ulceration of the coagulated surface with an adherent fibrin coagulum was noted in all patients 7 days after each APC treatment in both groups (fig. 1). There was no significant difference for the healing period of treatment ulcers in both groups (12.9 \pm 4.0 vs. $12.8 \pm 4.1$ days, $\mathrm{p}=0.91$ ).

The cumulative recurrence rates of EVs (24 and 36 months) after APC in the transnasal APC group (24.6 and $35.0 \%$ ) were as low as those in the peroral APC group (34.2 and $40.8 \%, \mathrm{p}=0.39$, log-rank test); this result demonstrates the non-inferiority of transnasal APC to peroral APC (fig. 2a).
The intraoperative effects on cardiorespiratory function were investigated using the vital sign parameters of BP, heart rate and $\mathrm{SpO}_{2}$ (fig. 2b). A 2-liter oxygen cannula was used to prevent hypoxemia during sedation only for patients in the peroral APC group. When the examination time lasted more than $10 \mathrm{~min}$, a transient elevation in $\mathrm{BP}$ and a drop in $\mathrm{SpO}_{2}$ were observed in the peroral APC group. In contrast, these vital signs were stable in the transnasal APC group. With regard to postoperative complications, hypertension $(>160 \mathrm{~mm} \mathrm{Hg}$ on systolic BP or $>100 \mathrm{~mm} \mathrm{Hg}$ on diastolic BP) was more frequently observed in the peroral APC group (transnasal vs. peroral APC group, 30 vs. $54.9 \%, \mathrm{p}=0.05$, Fisher's exact test). Moreover, the transnasal APC group had a significantly lower incidence of complications, such as epigastralgia ( 52.5 vs. $75.8 \%, p=0.01$ ). Epistaxis occurred in 1 patient, but immediately and spontaneously stopped.

\section{Discussion}

We set out to evaluate prospectively whether transnasal endoscopic APC without sedation is more effective than peroral endoscopic APC with sedation. In order to prevent variceal recurrence, it is necessary to resect the small collateral veins of the distal esophageal mucosa, a site which has a propensity to form varicose veins. For this purpose, mucosal fibrosis therapy was often undertaken as the consolidation therapy after EIS or EVL [17]. The technique previously used was perivariceal sclerotherapy with $1 \%$ polidocanol [18]. Recently, APC has superseded this for achieving mucosal fibrosis to prevent the recurrence of EVs $[19,20]$. APC is a very effective method, although it requires sedation for reducing patient distress. For LC patients, sedation is a risk factor for inducing the prolongation of hepatic encephalopathy [4]. Concerning this point, our new APC method using a transnasal endoscope was superior to the peroral method, because the former did not require sedation. The degree of patient distress in the transnasal APC group was investigated using visual analog scales (VAS) for pharyngeal pain, choking sensation, nausea and fullness $(0$, no pain, to 10, maximum pain). Acceptable results were obtained in terms of mean pain VAS scores: $1.7 \pm 1.5$ for pharyngeal pain, $1.7 \pm 1.8$ for choking sensation, $0.8 \pm$ 1.3 for nausea and $3.3 \pm 3.0$ for fullness. The APC treatment with the transnasal endoscope indicated a high acceptability for LC patients, even without sedation.

Since the diameter of the APC axial probe for the transnasal endoscope was relatively small, the output 


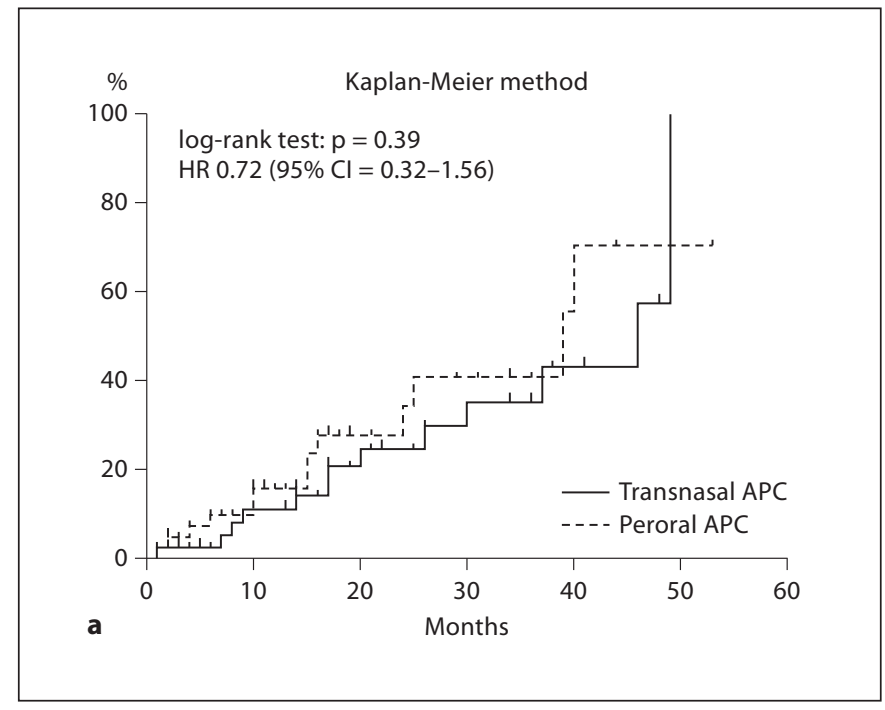

Fig. 2. a Cumulative recurrence rate of EVs after transnasal and peroral APC. The cumulative recurrence rate of EVs in the transnasal APC group was as low as that in the peroral APC group ( $p=0.39, \log$-rank test $)$ and the non-inferiority of the transnasal APC procedure was demonstrated. A p value of less than 0.05 was considered to indicate a statistically significant difference. b Intraoperative vital signs during APC. The intraoperative effects on the cardiorespiratory function were investigated using the vital sign parameters of $\mathrm{BP}$, heart rate and $\mathrm{SpO}_{2}$. A 2-liter oxygen cannula was used to prevent hypoxemia during sedation only for patients in the peroral APC group. When the examination time lasted more than $8 \mathrm{~min}$, a transient elevation in $\mathrm{BP}$ and a drop in $\mathrm{SpO}_{2}$ were observed in the peroral group. The solid diamonds represent transnasal APC and the open squares represent peroral APC.

power and argon gas flow rate had limitations. However, the recurrence rate of EVs after transnasal APC was as low as that after peroral APC, and the non-inferiority in the recurrence rate was demonstrated in this study.

LC patients are often accompanied by arterialization of the liver [21], intrahepatic shunts [22], pulmonary arteriovenous shunts [23] and a hyperdynamic circulatory state with a characteristic increase in cardiac output [24]. Therefore, elevation of $\mathrm{BP}$ or reduction in $\mathrm{SpO}_{2}$ during sedation has the possibility of having a negative effect on these hemodynamic changes $[25,26]$. In this study, BP and $\mathrm{SpO}_{2}$ in the transnasal APC group were more stable than those in the peroral APC group, indicating that transnasal APC was suitable for LC patients. Moreover, the incidence of complications in the transnasal APC group was lower than that in the peroral APC group.

Transnasal Argon Plasma Coagulation

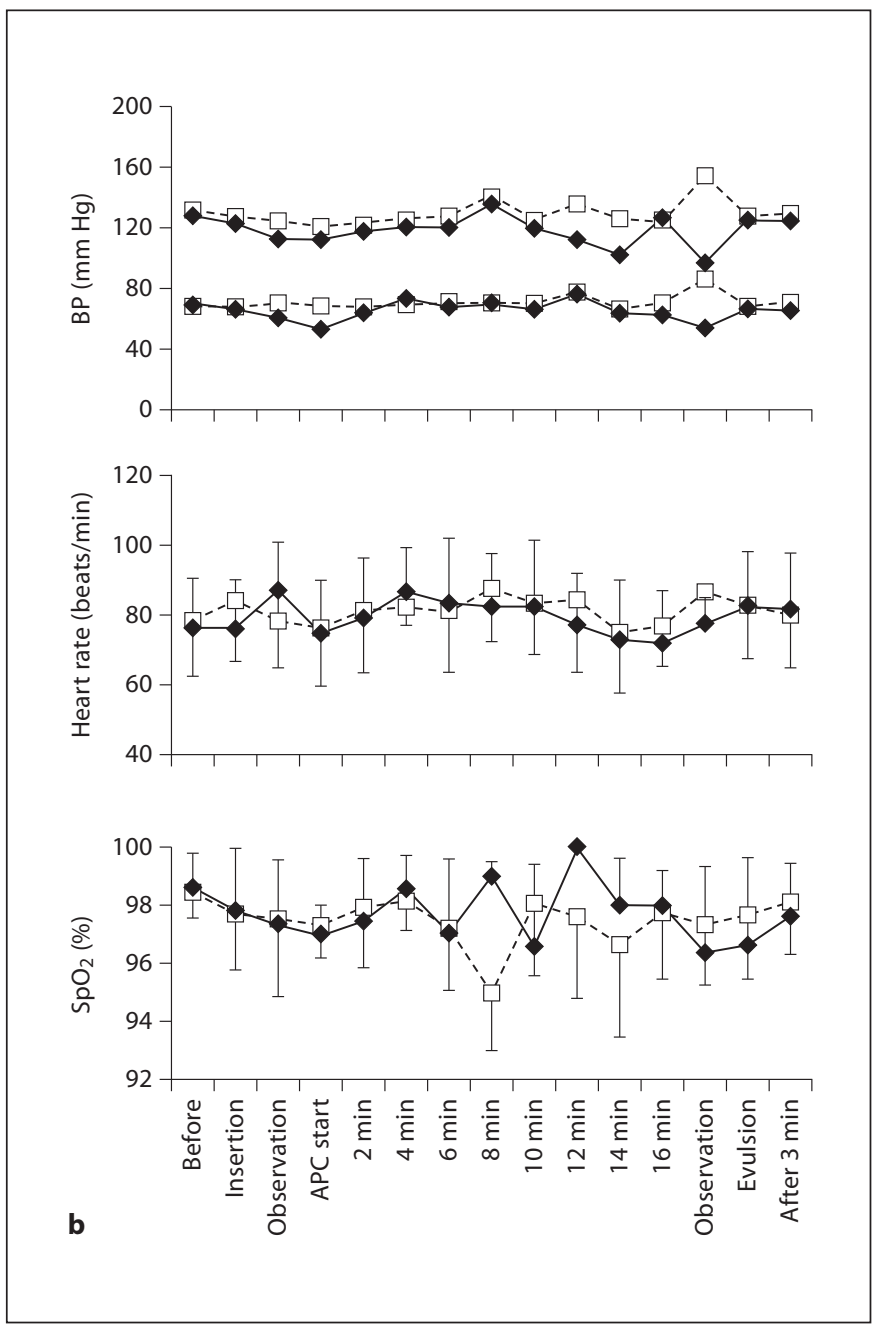

Although this study found that APC treatment using a transnasal endoscope was beneficial for LC patients, the fact that it was carried out at a single institution does present a limitation. A multicenter prospective study to investigate the effectiveness of transnasal APC is warranted.

\section{Conclusion}

Transnasal APC demonstrated several advantages. It results in a low recurrence rate of EVs, it causes almost no pain, it requires no sedation with the accompanying risk of hepatic encephalopathy, it allows stable intraoperative $\mathrm{BP}$ as well as stable $\mathrm{SpO}_{2}$, and it causes less frequent complications. This method is a promising and beneficial future therapeutic strategy for EVs. 


\section{Acknowledgements}

We are indebted to Dr. Clifford A. Kolba (D.O., D.Ed., M.P.H., C.P.H.) and Dr. Edward F. Barroga (PhD, Associate Professor) of the Department of International Medical Communications of Tokyo Medical University, for their editorial review of the English manuscript. This study was partially supported by a Health and Labour Sciences Research Grant from the Ministry of Health, Labour and Welfare of Japan for Research on Intractable Diseases and Portal Hemodynamic Abnormalities.

\section{Disclosure Statement}

None of the authors have any conflicts of interest associated with this study.

\section{References}

1 Nakamura S, Mitsunaga A, Murata Y, Suzuki S, Hayashi N: Endoscopic induction of mucosal fibrosis by argon plasma coagulation (APC) for esophageal varices: a prospective randomized trial of ligation plus APC vs. ligation alone. Endoscopy 2001;33:210-215.

- Cipolletta L, Bianco MA, Rotondano G, Marmo R, Meucci C, Piscopo R: Argon plasma coagulation prevents variceal recurrence after band ligation of esophageal varices: preliminary results of a prospective randomized trial. Gastrointest Endosc 2002;56:467471.

- 3 Johanns W, Luis W, Janssen J, Kahl S, Greiner L: Argon plasma coagulation (APC) in gastroenterology: experimental and clinical experiences. Eur J Gastroenterol Hepatol 1997;9:581-587.

-4 Assy N, Rosser BG, Grahame GR, Minuk GY: Risk of sedation for upper GI endoscopy exacerbating subclinical hepatic encephalopathy in patients with cirrhosis. Gastrointest Endosc 1999;49:690-694.

5 Thulivath PJ: Toward safer sedation in patients with cirrhosis: have we done enough? Gastrointest Endosc 2009;70:269-271.

-6 Riphaus A, Lechowicz I, Frenz MB, Wehrmann T: Propofol sedation for upper gastrointestinal endoscopy in patients with liver cirrhosis as an alternative to midazolam to avoid acute deterioration of minimal encephalopathy: a randomized controlled study. Scand J Gastroenterol 2009;44:1244 1251.

7 Khamaysi I, William N, Olga A, Alex I, Vladimir M, Kamal D, et al: Sub-clinical hepatic encephalopathy in cirrhotic patients is not aggravated by sedation with propofol compared to midazolam: a randomized controlled study. J Hepatol 2011;54:72-77.

-8 Qadeer MA, Lopez AR, Dumot JA, Vargo JJ: Hypoxemia during moderate sedation for gastrointestinal endoscopy: causes and associations. Digestion 2011;84:37-45. $\checkmark 9$ Khalid-de Bakker CA, Jonkers DM, Hameeteman W, de Ridder RJ, Masclee AA, Stockbrugger RW: Cardiopulmonary events during primary colonoscopy screening in an average risk population. Neth J Med 2011;69: 186-191.

10 Agusti AGN, Rosa J, Bosch J, Rodriguez-Roisin R: The lung in patients with cirrhosis. J Hepatol 1990;10:251-257.

11 Aharma P, Singh S, Sharma BC: Propofol in patients with cirrhosis and minimal hepatic encephalopathy. J Hepatol 2011;54:13211322.

12 Garcia RT, Cello JP, Nguyen MH, et al: Unsedated ultrathin EGD is well accepted when compared with conventional sedated EGD: a multicenter randomized trial. Gastroenterology 2003;125:1606-1612.

13 Grade A, Shah I, Medlin S, Ramirez F: The efficacy and safety of argon plasma coagulation therapy in Barrett's esophagus. Gastrointest Endosc 1999;50:18-22.

14 Watson JP, Bennett MK, Griffin SM, Matthewson K: The tissue effect of argon plasma coagulation on esophageal and gastric mucosa. Gastrointest Endosc 2002;52:342-345.

15 Harras F, Shazly ES, Shehata M, Saadany SE, Selim M, Mansour L: Endoscopic band ligation plus argon plasma coagulation versus scleroligation for eradication of esophageal varices. J Gastroenterol Hepatol 2010;25 1058-1065.

16 Hou MC, Lin HG, Lee FY, Chang FY, Lee SD: Recurrence of esophageal varices following endoscopic treatment and its impact on rebleeding: comparison of sclerotherapy and ligation. J Hepatol 2000;32:202-208.

17 Lo GH, Lai KH, Cheng JS, Huang RL, Wang SJ, Chiang HT: Prevalence of paraesophageal varices and gastric varices in patients achieving variceal obliteration by banding ligation and by injection sclerotherapy. Gastrointest Endosc 1999;49:428-437.
18 Matsumoto H, Toyonaga A, Oho K, et al: Ligation plus low volume sclerotherapy for high risk esophageal varices: comparisons with ligation therapy or sclerotherapy alone. J Gastroenterol 1998;33:1-5.

19 Furukawa K, Aoyagi Y, Harada T, Enomoto $\mathrm{H}$ : The usefulness of prevention consolidation therapy of esophageal varices using an argon plasma coagulation technique. Hepatology Research 2002;23:220-225.

20 Matsui S, Kudo M, Nakaoka R, Shiomi M, Kawasaki T: Comparison of argon plasma coagulation and paravariceal injection sclerotherapy with $1 \%$ polidocanol in mucosa-fibrosing therapy for esophageal varices. J Gastroenterol 2004;39:397-401

21 Zoli M, Magalotti D, Bianchi G, et al: Functional hepatic flow and Doppler-assessed total hepatic flow in control subjects and in patients with cirrhosis. J Hepatol 1995;23:129134

22 Ohnishi K, Chin N, Saito M, et al: Portographic opacification of hepatic veins and anomalous anastomoses between the portal and hepatic veins in cirrhosis - indication of extensive intrahepatic shunts. Am J Gastroenterol 1986;81:975-978.

23 Agusti AGN, Rosa J, Bosch J, Rodriguez-Roisin R: The lung in patients with cirrhosis. J Hepatol 1990;10:251-257.

- 24 Kontos HA, Shapiro W, Mauck HP, Patterson JL: General and regional circulatory alterations in cirrhosis of the liver. Am J Med 1964;37:526-535.

-25 Palma DT, Philips GM, Arguedas MR, Harding SM, Fallon MB: Oxygen desaturation during sleep in hepatopulmonary syndrome. Hepatology 2008;47:1257-1263

26 Kawai T, Miyazaki I, Yagi K, Kataoka M, Kawakami K, Yamagishi T, et al: Comparison of the effects on cardiopulmonary function of ultrathin transnasal versus normal diameter transoral esophagogastroduodenoscopy in Japan. Hepatogastroenterology 2007;54:770-774. 